\title{
SALVAR MADRES Y REC IÉN NACIDOS: CONVOCATORIA DE PROYECTOS DE LA FIGO
}

FIGO convoca a todas las sociedades nacionales de Obstetricia y Ginecología a presentar propuestas de proyectos de una duración de tres a cinco años en el campo de salud maternal y de recién nacidos. Los proyectos han de destinarse a naciones de ingresos bajos y medianos, y, siempre que sea posible, se realizarán con la colaboración de las correspondientes asociaciones profesionales de matronas*. En esta iniciativa también son aceptables las colaboraciones entre países de grandes recursos y países de ingresos bajos y medianos. Más abajo puede leerse un resumen de la iniciativa. Además, en el enclave de www.figo.org se encontrará mayor información relativa a la conformación que se desea que revistan las propuestas. La fecha límite para la recepción de propuestas es el $1^{\circ}$ de noviembre de 2004 . Las propuestas deberán estar redactadas en cualquiera de los idiomas inglés, francés o español.

\section{RESUMEN DEL PROYECTO}

Antecedentes. Este proyecto quinquenal es la segunda generación de proyectos nacionales, y se cimenta sobre las recientes experiencias de la iniciativa "Salvemos las Madres" (1998-2003), durante la cual, FIGO apoyó los proyectos de cinco sociedades nacionales de Obstetricia y Ginecología en naciones de bajos ingresos cuyo objetivo era procurar cuidados obstétricos de emergencia en zonas establecidas. Estos proyectos se llevaron a cabo mediante hermanamientos con sociedades en naciones de altos ingresos.

El proyecto vigente es un paso más allá en la involucración de las sociedades nacionales en programas de mejora de la salud maternal y de los recién nacidos:

1. Apoyando a las asociaciones profesionales de países en vías de desarrollo para que creen y pongan en práctica proyectos de su propia elec-

* En este documento se utiliza "matrona" como profesional de la salud con el rango de enfermera o superior y con capacitación obstétrica. Dependiendo del país, también se alude a este profesional de la salud como "enfermera obstetra", "obstetriz" o "matrona". ción y diseño en el campo de la salud del recién nacido o de la maternidad sin riesgo.

2. Estimulando el trabajo conjunto a nivel nacional, especialmente con asociaciones de matronas y otras asociaciones nacionales interesadas, así como el hermanamiento con sociedades más experimentadas en Obstetricia y Ginecología.

Mediante un procedimiento solicitud en dos fases, las sociedades nacionales de Obstetricia y Ginecología de países de ingresos bajos y medianos podrán obtener apoyo para desarrollar sus propuestas de proyectos (fase 1) y para la puesta en práctica del programa en un período de tres a cinco años (fase 2). El apoyo inicial (fase 1) para el desarrollo del proyecto completo incluye una pequeña beca (EE.UU. \$2000) y la ayuda de un asesor externo. La suma destinada al propio proyecto (véase más abajo) sólo podrá adjudicarse una vez que tal proyecto haya recibido el beneplácito del comité de la FIGO.

El objetivo general es el de contribuir a la reducción de los índices de morbilidad y mortalidad de madres y recién nacidos. Los objetivos secundarios son los siguientes: Fortalecer la capacidad de las sociedades profesionales del país para ocuparse de la salud de madres y neonatos a través de la elaboración y puesta en práctica de proyectos en este campo, confirmando así su competencia como organizaciones a escala nacional. Las sociedades nacionales recibirán apoyo para la elaboración de sus proyectos, concentrándose en sus respectivas prioridades nacionales en el terreno de la salud de madres-recién nacidos, con el enunciado de posibles ejemplos a seguir. Es muy de desear que los resultados del proyecto puedan ser conmensurables desde el punto de vista del cliente/paciente, y, cuando sea posible, se valore su efecto en los programas y políticas nacionales.

El proyecto está plenamente alineado con los Objetivos de Desarrollo para el Milenio, y al fortalecer la participación de la sociedad civil en este terreno, es muy oportuno en una época de creciente amalgamación de los sectores público y privado.

Plazos y presupuesto. Se propone que el proyecto se extienda por un plazo inicial de 3 a 5 años, y que participen 10 sociedades nacionales 
(además de sus "hermanas"). Se espera que cada proyecto aprobado disfrute de un presupuesto de EE.UU. \$ 50,000 - 100,000 anuales. Un $20 \%$ de este total se recaudará localmente (que puede incluir el trabajo de los propios miembros); la FIGO contribuirá con un $10 \%$ en metálico, y el resto será recaudado por la FIGO de fuentes externas.

Los resultados esperados son la reducción de la mortalidad y morbilidad maternas y de los recién nacidos; un mejor acceso a los cuidados sanitarios de madres y recién nacidos; aumento de la capacidad y la credibilidad de las asociaciones nacionales de profesionales (obstetras, ginecólogos, matronas) y de sus correspondientes federaciones y internacionales en la organización de proyectos de maternidad segura, y el incremento de la colaboración entre obstetras y ginecólogos y matronas.

Informaciones: Para total información, consulte www.figo.org "Saving Mothers and Newborns" 